\title{
First-in-man randomised comparison of the BuMA Supreme biodegradable polymer sirolimus-eluting stent versus a durable polymer zotarolimus-eluting coronary stent: the PIONEER trial
}

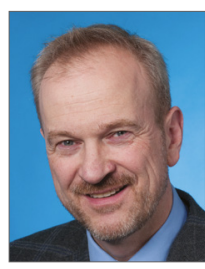

Clemens von Birgelen ${ }^{1}, \mathrm{MD}, \mathrm{PhD}$; Taku Asano ${ }^{2,3}, \mathrm{MD}$; Giovanni Amoroso ${ }^{4}, \mathrm{MD}, \mathrm{PhD}$;

Adel Aminian 5 , MD; Salvatore Brugaletta ${ }^{6}, \mathrm{MD}, \mathrm{PhD}$; Mathias Vrolix ${ }^{7}, \mathrm{MD}$;

Rosana Hernandez-Antolín ${ }^{8}$, MD, PhD; Pim van de Harst ${ }^{9,10}, \mathrm{MD}, \mathrm{PhD}$;

Andres Iñiguez ${ }^{11}, \mathrm{MD}, \mathrm{PhD}$; Luc Janssens ${ }^{12}, \mathrm{MD}$; Pieter C. Smits ${ }^{13}, \mathrm{MD}, \mathrm{PhD}$;

Joanna J. Wykrzykowska², MD, PhD; Vasco Gama Ribeiro ${ }^{14}$, MD; Hélder Pereira ${ }^{15}$, MD;

Pedro Canas da Silva ${ }^{16}$, MD; Jan J. Piek ${ }^{2}, \mathrm{MD}$, PhD; Yoshinobu Onuma ${ }^{17,18}, \mathrm{MD}, \mathrm{PhD}$;

Patrick W. Serruys ${ }^{19 *}, \mathrm{MD}, \mathrm{PhD}$; Manel Sabaté 6 , MD, PhD

1. Thoraxcentrum Twente, Enschede, the Netherlands; 2. Academic Medical Center, University of Amsterdam, Amsterdam, the Netherlands; 3. St. Luke's International Hospital, Tokyo, Japan; 4. Onze Lieve Vrouwe Gasthuis, Amsterdam, the Netherlands;

5. Centre Hospitalier Universitaire de Charleroi, Charleroi, Belgium; 6. Clinic University Hospital, Cardiovascular Clinic Institute, Institut d'Investigacions Biomèdiques August Pi i Sunyer (IDIBAPS), Barcelona, Spain; 7. Oost Limburg Hospital, Genk, Belgium; 8. Ramón y Cajal University Hospital, Madrid, Spain; 9. University of Groningen, Groningen, the Netherlands; 10. University Medical Center Groningen, Groningen, the Netherlands; 11. Hospital Alvaro Cunqueiro, Vigo, Spain; 12. Imelda Hospital Bonheiden, Bonheiden, Belgium; 13. Maasstad Hospital, Rotterdam, the Netherlands; 14. Gaia/Espinho Hospital Centers, Oporto, Portugal; 15. Hospital Garcia de Orta, Almada, Portugal; 16. Santa Maria University Hospital - North Lisbon Hospital Center, Lisbon, Portugal; 17. Thoraxcenter, Erasmus Medical Center, Rotterdam, the Netherlands; 18. Cardialysis, Rotterdam, the Netherlands; 19. NHLI, Imperial College London, London, United Kingdom

C. von Birgelen and T. Asano contributed equally to this manuscript.

GUEST EDITOR: Adnan Kastrati, MD; Deputy Director of Department Cardiovascular Diseases, Deutsches Herzzentrum München, Munich, Germany

This paper also includes supplementary data published online at: http://www.pcronline.com/eurointervention/132nd_issue/332

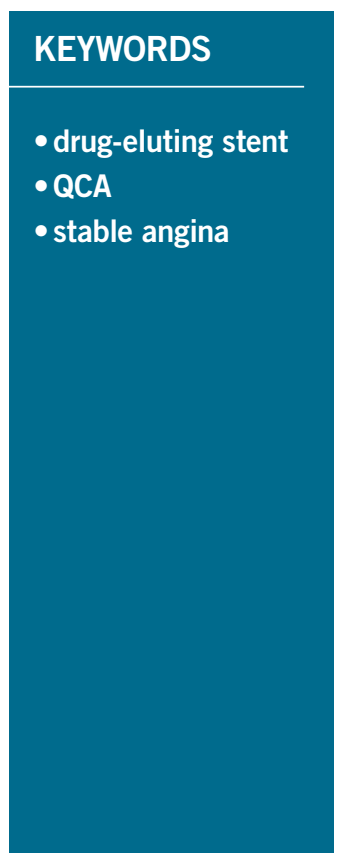

\section{Abstract}

Aims: A second iteration of a sirolimus-eluting stent (SES) that has a biodegradable PLGA polymer coating with an electrografting base layer on a thin-strut $(80 \mu \mathrm{m})$ cobalt-chromium platform (BuMA Supreme; SINOMED, Tianjin, China) has been developed. This first-in-man trial aimed to assess the efficacy and safety of the novel device.

Methods and results: This randomised, multicentre, single-blinded, non-inferiority trial compared the BuMA Supreme SES versus a contemporary durable polymer zotarolimus-eluting stent (ZES) in terms of angiographic in-stent late lumen loss (LLL) at nine-month follow-up as the primary endpoint. A total of 170 patients were randomly allocated to treatment with either SES $(n=83)$ or ZES $(n=87)$. At nine-month angiographic follow-up, in-stent LLL was $0.29 \pm 0.33 \mathrm{~mm}$ in the SES group and $0.14 \pm 0.37 \mathrm{~mm}$ in the ZES group $\left(\mathrm{p}_{\text {non-inferiority }}=0.45\right)$. The in-stent percent diameter stenosis and the binary restenosis rate of the two treatment arms were similar $(19.2 \pm 12.0 \%$ vs. $16.1 \pm 12.6 \%, \mathrm{p}=0.09$, and $3.3 \%$ vs. $4.4 \%, \mathrm{p}=1.00$, respectively). At 12-month clinical follow-up, there was no difference between treatment arms with regard to the device-oriented composite clinical endpoint ( $4.9 \%$ vs. $5.7 \%$; $\mathrm{p}=0.72)$.

Conclusions: The PIONEER trial did not meet its primary endpoint in terms of in-stent LLL at ninemonth follow-up. However, this result did not translate into any increase in restenosis rate or impairment in 12-month clinical outcomes.

\footnotetext{
*Corresponding author: Cardiovascular Science Division of the NHLI within Imperial College of Science, Technology and Medicine, South Kensington Campus, London, SW7 2AZ, United Kingdom. E-mail: patrick.w.j.c.serruys@gmail.com
} 


\section{Abbreviations}

BP biodegradable polymer

CD cardiac death

CI-TLR clinically indicated TLR

DES drug-eluting stent

DoCE device-oriented composite endpoint

DS diameter stenosis

LLL late lumen loss

OCT optical coherence tomography

QCA quantitative coronary angiography

SES sirolimus-eluting stent

TIMI Thrombolysis In Myocardial Infarction

TLR target lesion revascularisation

TV-MI target vessel myocardial infarction

ZES zotarolimus-eluting stent

\section{Introduction}

Second-generation drug-eluting stents (DES) have been developed with more biocompatible durable polymer coatings on thinstrut stents and have demonstrated improved safety relative to first-generation $\mathrm{DES}^{1-3}$. Biodegradable polymer (BP)-DES were developed to reduce long-term polymer-related adverse effects ${ }^{4}$.
Several studies have shown improvement of clinical outcomes with BP-DES as compared to durable polymer DES ${ }^{4}$.

The BuMA ${ }^{\mathrm{TM}}$ Supreme (SINOMED, Tianjin, China) sirolimuseluting stent (SES) consists of a thin-strut cobalt-chromium platform $(80 \mu \mathrm{m})$ with a thin $(200 \mathrm{~nm})$ electrografted base layer, to which a biodegradable top coat is firmly adhered. The base layer is bonded to the stent surface and both anchors and aligns the molecule of the biodegradable top layer. This prevents the bioactive coating from cracking and delamination upon delivery and expansion of the stent (Figure 1). The BuMA Supreme SES has a pharmacokinetic polymer degradation/drug release profile where the top coat releases the drug relatively rapidly such that sirolimus release from the stent surface is nearly complete by 28 days after implantation. Less than $1 \mathrm{ng} / \mathrm{mg}$ of the drug is maintained in the arterial wall at 60 days after implantation (Figure 2). Several studies in humans and animal models have demonstrated the efficacy and safety of its predecessor, the BuMA stent, which used a stainless steel platform of $100 \mu \mathrm{m}^{5}$.

The present first-in-man study assessed nine-month angiographic and 12-month clinical endpoints to evaluate the efficacy and safety of the BuMA Supreme SES versus a durable BioLinx $^{\mathrm{TM}}$ (Medtronic, Santa Rosa, CA, USA) tripolymer-coated
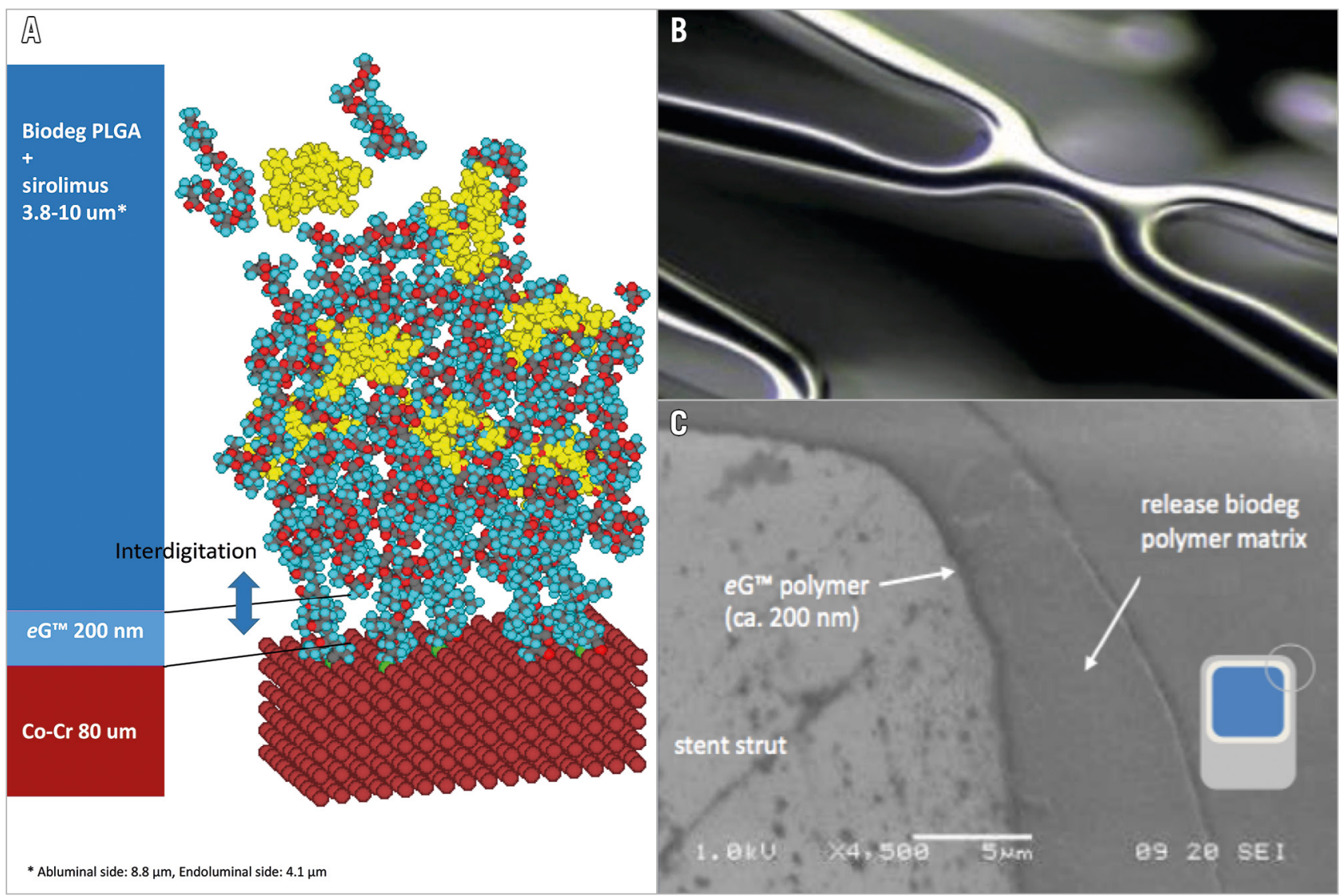

Figure 1. The BuMA Supreme stent design. A) Electrografting coating technology (eG): polymer chains (200 nm) of poly n-butyl methacrylate covalently bound by electrografting to an electronically polished thin-strut ( $80 \mu \mathrm{m})$ cobalt-chromium stent platform. B) Link between cells. C) Electron microscopy (×4,500) showing strut of BuMA Supreme (left), electrografted base layer (eG) (mid) and polymer matrix of PLGA containing sirolimus. 


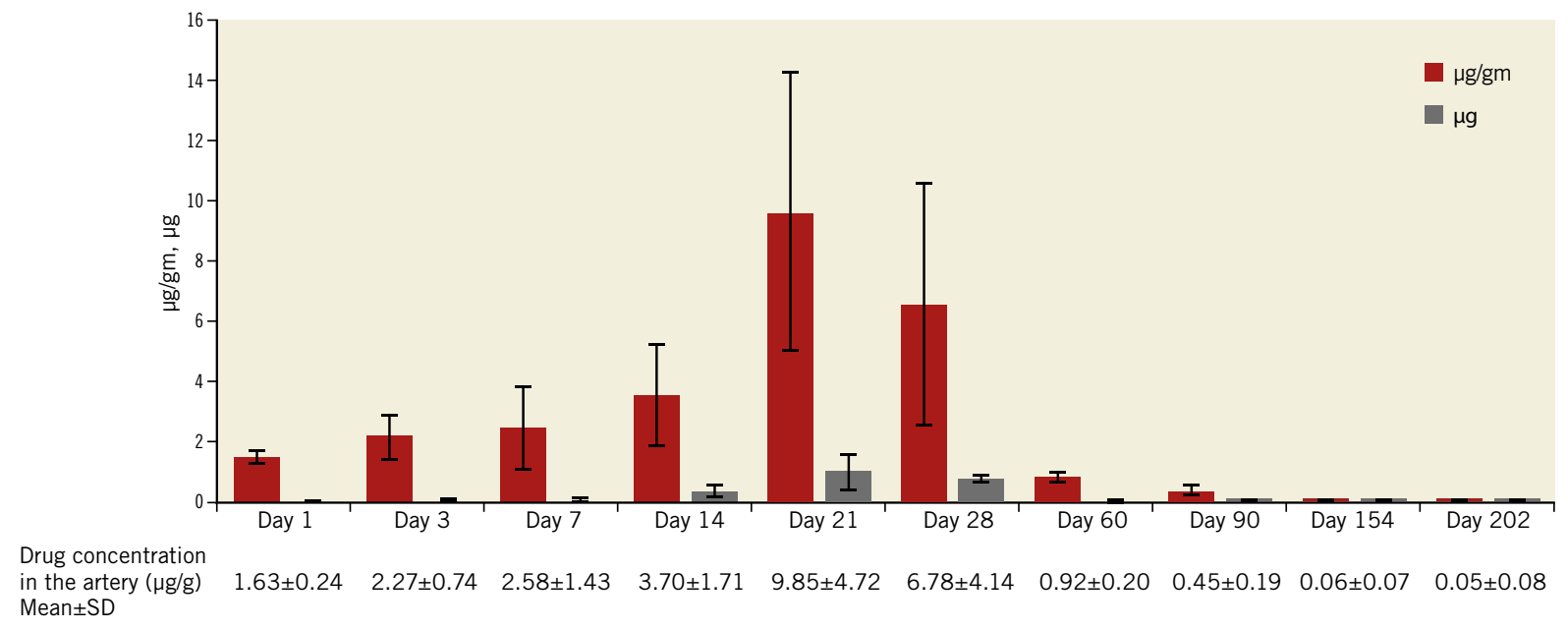

Figure 2. Pharmacokinetics of the artery after implantation of the BuMA Supreme SES (porcine model). Stented artery segment sirolimus concentration peaked up to 21 days. Peak correlates with polymer degradation and with blood levels.

(Resolute-type) zotarolimus-eluting stent (ZES). The latter device has shown favourable outcomes in randomised trials ${ }^{6,7}$.

\section{Methods STUDY DESIGN AND POPULATION}

The PIONEER trial is a multicentre, single-blinded, two-arm 1:1 randomised trial, which was designed to demonstrate non-inferiority of the BuMA Supreme SES versus a Resolute-type ZES in terms of nine-month angiographic in-stent late lumen loss (LLL). In addition, secondary clinical endpoints were assessed at 12-month follow-up.

Patients were eligible for study enrolment if they met eligibility criteria, the details of which are listed in the Supplementary Appendix. Briefly, patients who presented with stable or unstable angina or silent ischaemia with one or two separate, de novo target lesions in a reference vessel of 2.5-4.5 mm were enrolled in the current trial. Patients with evolving myocardial infarction, bifurcated target lesion, target lesion in left main artery, aorto-ostial target lesion and restenotic target lesion were not eligible for the current trial.

The PIONEER study complied with the Declaration of Helsinki, medical ethics committees at each participating institution approved the trial, and all patients provided written informed consent.

\section{STUDY DEVICES AND IMPLANTATION PROCEDURE}

The BuMA Supreme SES is a DES with a rapid exchange balloon-expandable catheter delivery system. The device consists of an extremely thin (200 nm) electrografted (eG) base layer of poly(nbutyl methacrylate) (PBMA), perpendicularly and covalently bound to an electronically polished thin-strut $(80 \mu \mathrm{m})$ cobalt-chromium stent platform. The base layer forms a thin brush that interdigitates with a 3.8-10 $\mu$ m-thin top layer - a blend of a biodegradable polylactide-co-glycolic acid (PLGA) polymer and the drug sirolimus (drug concentration: $120 \mu \mathrm{g} / \mathrm{cm}^{2}$ of stent surface). The PLGA polymer layer is designed to resorb in six weeks (Figure 1) ${ }^{8}$.
Resolute-type ZES (Resolute Integrity ${ }^{\circledR}$ or Onyx ${ }^{\mathrm{TM}}$; both Medtronic, Minneapolis, MN, USA) were used in the control group. Resolute Integrity is made from a round cobalt-chromium wire $(91 \mu \mathrm{m})$ and Resolute Onyx from a swaged-shape core wire $(81 \mu \mathrm{m})$ that consists of a platinum-iridium core surrounded by cobalt-chromium. Both iterations of Resolute-type ZES elute zotarolimus over a six-month period ${ }^{6,7,9-11}$. Interventional procedure was performed and dual antiplatelet therapy was administered according to current clinical guidelines.

\section{ENDPOINTS}

The primary study endpoint was in-stent LLL at nine months after stent implantation, as assessed by off-line quantitative coronary angiography (QCA) in at least two paired matched views. Secondary angiographic endpoints included acute lumen gain, insegment LLL at nine months, minimum lumen diameter post procedure and at nine months, percent diameter stenosis (DS) post procedure and at nine months, and binary restenosis (DS $\geq 50 \%$ ) at nine months. All measurements were performed in-stent, in-segment, and on the $5 \mathrm{~mm}$ proximal and distal stent margins.

Secondary clinical endpoints included: 1) acute device success, 2) procedural success, and 3) a device-oriented composite endpoint (DoCE), defined as the composite of cardiac death, target vessel myocardial infarction (TV-MI), and clinically indicated target lesion revascularisation (CI-TLR). Each definition is described in the Supplementary Appendix. Stent thrombosis was defined according to Academic Research Consortium (ARC) definitions ${ }^{12}$ and was assessed as a secondary endpoint. MI was defined according to the criteria of the third universal definition ${ }^{13}$ except for MI type $4 \mathrm{a}$ (periprocedural MI), for which the SCAI definition ${ }^{14}$ was used.

An independent clinical events committee adjudicated the clinical endpoints; an independent data safety monitoring board supervised the trial. Angiographic follow-up was performed at nine months. Patients were clinically followed at 1, 9, and 12 months. 
The trial was monitored by an independent clinical research organisation (Cardialysis, Rotterdam, the Netherlands).

\section{QUANTITATIVE CORONARY ANGIOGRAPHY ANALYSIS}

Off-line QCA analysis was performed by an independent core laboratory (Cardialysis, Rotterdam, the Netherlands) using the CAAS system (Pie Medical Imaging, Maastricht, the Netherlands) according to standard protocols. If the target lesion was revascularised at any time between baseline and nine months, the prerevascularisation angiogram was analysed.

\section{STATISTICAL ANALYSIS}

Categorical variables were reported as counts and percentages, and between-group differences were assessed by $\chi^{2}$ test or Fisher's exact test, as appropriate. Continuous variables were presented as mean \pm SD and compared with a t-test. Unless otherwise specified, a two-sided p-value $<0.05$ was considered statistically significant. The statistical analysis was performed by SAS, version 9.3 (SAS Institute, Cary, NC, USA). Sample size calculation of the trial is described in the Supplementary Appendix.

\section{Results}

\section{BASELINE AND PROCEDURAL CHARACTERISTICS}

From April 2015 to January 2016, 170 patients were enrolled and randomly assigned to treatment with the BuMA Supreme SES (83 patients, 95 lesions) or Resolute-type ZES (87 patients, 101 lesions) (Figure 3). Patient demographics and clinical characteristics are shown in Table 1. Details of the interventional procedures are presented in Supplementary Table 1.
Table 1. Study population.

\begin{tabular}{|l|c|c|c|}
\hline & $\begin{array}{c}\text { BuMA } \\
\text { Supreme } \\
\text { SES (N=83) }\end{array}$ & $\begin{array}{c}\text { Resolute- } \\
\text { type } \\
\text { ZES (N=87) }\end{array}$ & $\begin{array}{c}\text { Difference } \\
\text { [95\% Cl] }\end{array}$ \\
\hline Age, years & $64.3 \pm 8.9$ & $62.5 \pm 9.3$ & $1.7[-1.0,4.5]$ \\
\hline Male sex & $62(74.7)$ & $64(73.6)$ & $1.1[-12.0,14.3]$ \\
\hline BMI & $27.8 \pm 4.8$ & $27.8 \pm 4.2$ & $0.1[-1.3,1.4]$ \\
\hline
\end{tabular}

\section{Coexisting condition}

\begin{tabular}{|c|c|c|c|}
\hline Diabetes mellitus & $24(28.9)$ & $20(23)$ & $5.9[-7.2,19.1]$ \\
\hline Insulin-treated diabetes & $10(12.0)$ & $6(6.9)$ & $5.2[-3.6,13.9]$ \\
\hline Non-insulin-treated diabetes & $14(16.9)$ & $14(16.1)$ & $0.8[-10.4,11.9]$ \\
\hline Hypertension & $47(56.6)$ & $57(65.5)$ & $-8.9[-23.5,5.7]$ \\
\hline Dyslipidaemia*\# & $54(65.1)$ & $53(61.6)$ & $3.4[-11.1,18.0]$ \\
\hline \multicolumn{4}{|l|}{ Current or previous smoker } \\
\hline Current smoker*\# & $21(25.6)$ & $22(25.6)$ & \\
\hline Previous smoker*\# & $35(42.7)$ & $35(40.7)$ & \\
\hline Family history of $C A D^{* \#}$ & $35(42.7)$ & $37(43.0)$ & $-0.3[-15.3,14.6]$ \\
\hline Previous myocardial infarction & $15(18.1)$ & $15(17.2)$ & $0.8[-10.6,12.3]$ \\
\hline $\begin{array}{l}\text { Previous percutaneous coronary } \\
\text { intervention }\end{array}$ & $18(21.7)$ & $16(18.4)$ & $3.3[-8.7,15.3]$ \\
\hline $\begin{array}{l}\text { Previous coronary artery bypass } \\
\text { grafting }\end{array}$ & $4(4.8)$ & $3(3.4)$ & $1.4[-4.6,7.4]$ \\
\hline COPD & $5(6.0)$ & $4(4.6)$ & $1.4[-5.3,8.2]$ \\
\hline
\end{tabular}

Initial clinical presentation

\begin{tabular}{|l|l|l|l|}
\hline Unstable angina & $20(24.1)$ & $15(17.2)$ & \\
\hline Stable angina & $42(50.6)$ & $52(59.8)$ & \\
\hline Silent ischaemia & $21(25.3)$ & $20(23.0)$ & \\
\hline
\end{tabular}

Data are expressed as mean \pm SD or number (percentage). *Missing data for one patient in SES arm. " Missing data for one patient in ZES arm. BMl: body mass index; CAD: coronary artery disease; COPD: chronic obstructive pulmonary disease

\begin{tabular}{|c|c|}
\hline \multicolumn{2}{|c|}{$\begin{array}{l}\text { PIONEER trial } \\
170 \text { patients randomised } \\
\text { Intention-to-treat analysis }\end{array}$} \\
\hline $\begin{array}{l}\quad \text { BuMA Supreme SES } \\
83 \text { patients (N) / } 95 \text { lesions }(\mathrm{L}) \\
\text { Available pre-procedure QCA (N=81, } \mathrm{L}=92) \\
\text { Available post-procedure QCA (N=82, } \mathrm{L}=93)\end{array}$ & $\begin{array}{l}\text { Resolute-type ZES } \\
\mathbf{8 7} \text { patients }(\mathbf{N}) / 101 \text { lesions }(\mathrm{L}) \\
\text { Available pre-procedure QCA }(\mathrm{N}=83, \mathrm{~L}=95) \\
\text { Available post-procedure QCA (N=84, } \mathrm{L}=98)\end{array}$ \\
\hline$\rightarrow \begin{array}{l}\text { Death }(\mathrm{N}=1, \mathrm{~L}=1) \\
\text { Refusal of invasive imaging investigation }(\mathrm{N}=4, \mathrm{~L}=4)\end{array}$ & $\rightarrow \begin{array}{l}\text { Death }(\mathrm{N}=2, \mathrm{~L}=3) \\
\text { Refusal of invasive imaging investigation }(\mathrm{N}=5, \mathrm{~L}=5) \\
\text { Patient did not return for } 9 \text {-month follow-up }(\mathrm{N}=1, \mathrm{~L}=1)\end{array}$ \\
\hline $\begin{array}{l}\text { 9-month angiographic follow-up } \\
\text { Available QCA ( } N=78, \mathrm{~L}=90) \\
\text { Late loss using matched projection available } \\
\text { on } 87 \text { lesions. } \\
\text { Late loss using matched and non-matched } \\
\text { projection available on } 88 \text { lesions }\end{array}$ & $\begin{array}{l}\text { 9-month angiographic follow-up } \\
\text { Available QCA ( } N=79, \mathrm{~L}=91 \text { ) } \\
\text { Late loss using matched projection available } \\
\text { on } 87 \text { lesions. } \\
\text { Late loss using matched and non-matched projection } \\
\text { available on } 89 \text { lesions }\end{array}$ \\
\hline$\rightarrow \begin{array}{l}\text { Death }(\mathrm{N}=1) \\
\text { Patient did not return for 12-month clinical follow-up (N=1) }\end{array}$ & $\downarrow$ \\
\hline $\begin{array}{l}\text { 12-month clinical follow-up } \\
\text { Available data }(\mathrm{N}=82)\end{array}$ & $\begin{array}{l}\text { 12-month clinical follow-up } \\
\text { Available data }(\mathrm{N}=87)\end{array}$ \\
\hline
\end{tabular}

Figure 3. Study flow chart. 


\section{DEVICE AND PROCEDURAL SUCCESS}

Device success was achieved in 96.8\% (90/93) and 94.9\% (94/99) of lesions in the BuMA Supreme SES group and the Resolute-type ZES group, respectively. Seven lesions (two in the BuMA Supreme SES group and five in the Resolute-type ZES group) were treated with a non-study stent. One lesion in the BuMA Supreme SES group had a post-procedural residual stenosis $\geq 30 \%$ (Supplementary Table 1 ).

\section{NINE-MONTH ANGIOGRAPHIC FOLLOW-UP}

In the BuMA Supreme SES and the Resolute-type ZES groups, analyses of follow-up angiography were available in $94.7 \%(90 / 95)$ and $90.1 \%$ (91/101) of lesions, respectively (Figure 3). The primary endpoint of in-stent LLL was $0.29 \pm 0.33 \mathrm{~mm}$ in the BuMA Supreme SES group versus $0.14 \pm 0.37 \mathrm{~mm}$ in the Resolute-type ZES group $\left(\mathrm{p}_{\text {non-inferiority }}=0.45\right)$ (Table 2, Figure 4), which means that non-inferiority was not met. Nevertheless, this did not translate into a significant difference in the rates of in-stent or in-segment binary restenosis (Figure 5).

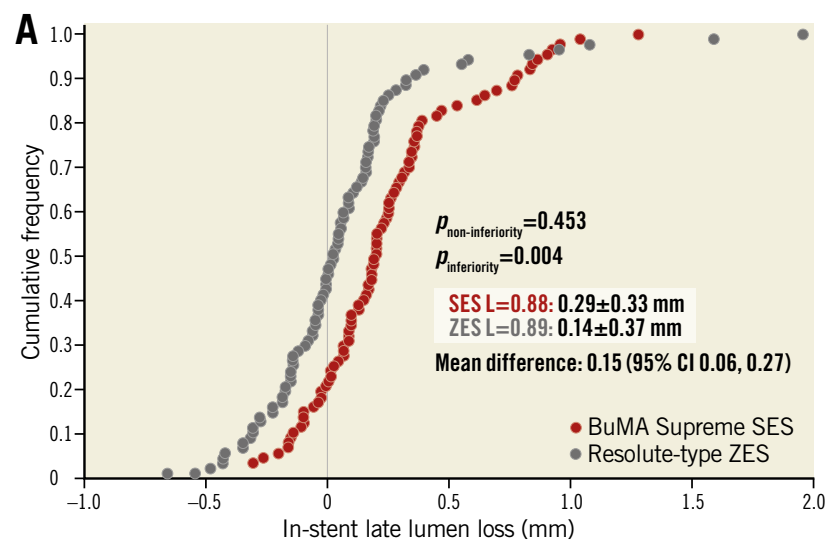

\section{TWELVE-MONTH CLINICAL OUTCOMES}

The 12-month clinical follow-up was available for 82 (98.8\%) patients of the SES group and $87(100 \%)$ patients in the Resolutetype ZES group (Figure 3). The incidence of DoCE was $4.9 \%$ $(4 / 82)$ in the BuMA Supreme SES group and 5.7\% (5/87) in the Resolute-type ZES group $(\mathrm{p}=1.00)$. CI-TLR was required in $2.4 \%(2 / 82)$ of the BuMA Supreme SES group versus $3.4 \%$ (3/87) of the Resolute-type ZES group $(p=1.00)$. In both stent arms, there were no cases of definite or probable stent thrombosis (Table 3).

\section{Discussion}

The main findings of the PIONEER trial are the following: 1) the criterion for non-inferiority of the primary angiographic endpoint (in-stent LLL) was not met; 2) nevertheless, in-stent and in-segment $\% \mathrm{DS}$ as well as the binary restenosis rate did not differ significantly between stent groups; and 3) the rates of the DoCE were similar in both treatment arms.

Figure 4. Cumulative frequency distribution curves of in-stent late lumen loss and in-segment late lumen loss at nine-month angiographic follow-up. A) In-stent late lumen loss. B) In-segment late lumen loss. Three LLL measurements based on unmatched views were included in this analysis (BuMA Supreme SES: 88 lesions, Resolute-type ZES: 89 lesions).
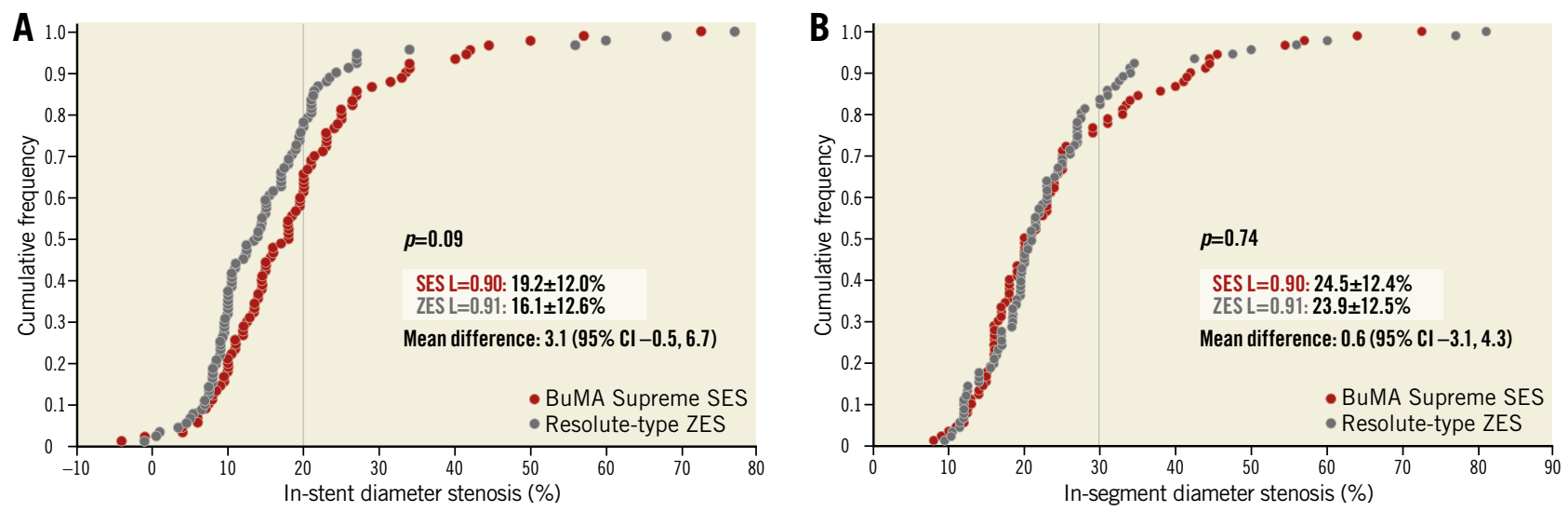

Figure 5. Cumulative frequency distribution curves of in-stent percent diameter stenosis and in-segment percent diameter stenosis at ninemonth angiographic follow-up. A) In-stent percent diameter stenosis. B) In-segment percent diameter stenosis. 
Table 2. Angiographic analysis.

\begin{tabular}{|c|c|c|c|c|c|c|c|c|c|c|c|c|}
\hline & \multicolumn{3}{|c|}{ Proximal edge } & \multicolumn{3}{|c|}{ In-stent } & \multicolumn{3}{|c|}{ Distal edge } & \multicolumn{3}{|c|}{ In-segment } \\
\hline & $\begin{array}{c}\text { SES } \\
(\mathrm{N}=95)\end{array}$ & $\begin{array}{c}\text { ZES } \\
(N=101)\end{array}$ & $p$-value & $\begin{array}{c}\text { SES } \\
(\mathrm{N}=95)\end{array}$ & $\begin{array}{c}\text { ZES } \\
(\mathrm{N}=101)\end{array}$ & $p$-value & $\begin{array}{c}\text { SES } \\
(\mathrm{N}=95)\end{array}$ & $\begin{array}{c}\text { ZES } \\
(N=101)\end{array}$ & $p$-value & $\begin{array}{c}\text { SES } \\
(\mathrm{N}=95)\end{array}$ & $\begin{array}{c}\text { ZES } \\
(N=101)\end{array}$ & $p$-value \\
\hline \multicolumn{13}{|c|}{ Reference vessel diameter ( $\mathrm{mm}$ ) } \\
\hline Pre-procedure & NA & NA & NA & $2.57 \pm 0.43$ & $2.66 \pm 0.48$ & 0.19 & NA & NA & NA & $2.57 \pm 0.43$ & $2.66 \pm 0.48$ & 0.19 \\
\hline Post-procedure & $2.86 \pm 0.42$ & $3.00 \pm 0.43$ & 0.034 & $2.68 \pm 0.39$ & $2.79 \pm 0.44$ & 0.07 & $2.57 \pm 0.40$ & $2.69 \pm 0.48$ & 0.08 & $2.60 \pm 0.40$ & $2.74 \pm 0.46$ & 0.027 \\
\hline At 9 months & $2.74 \pm 0.43$ & $2.97 \pm 0.47$ & 0.002 & $2.61 \pm 0.40$ & $2.79 \pm 0.46$ & 0.004 & $2.49 \pm 0.38$ & $2.71 \pm 0.48$ & $<0.001$ & $2.57 \pm 0.40$ & $2.75 \pm 0.46$ & 0.004 \\
\hline \multicolumn{13}{|c|}{ Mean lumen diameter (mm) } \\
\hline Post-procedure & $2.73 \pm 0.50$ & $2.81 \pm 0.51$ & 0.31 & $2.80 \pm 0.37$ & $2.89 \pm 0.41$ & 0.09 & $2.43 \pm 0.47$ & $2.52 \pm 0.49$ & 0.22 & $2.72 \pm 0.39$ & $2.81 \pm 0.42$ & 0.13 \\
\hline At 9 months & $2.64 \pm 0.51$ & $2.77 \pm 0.58$ & 0.13 & $2.60 \pm 0.39$ & $2.83 \pm 0.48$ & 0.001 & $2.47 \pm 0.45$ & $2.56 \pm 0.49$ & 0.24 & $2.58 \pm 0.39$ & $2.76 \pm 0.46$ & 0.005 \\
\hline \multicolumn{13}{|c|}{ Minimum lumen diameter (mm) } \\
\hline Pre-procedure & NA & NA & NA & $1.00 \pm 0.30$ & $1.03 \pm 0.34$ & 0.47 & NA & NA & NA & $1.00 \pm 0.30$ & $1.03 \pm 0.34$ & 0.47 \\
\hline Post-procedure & $2.47 \pm 0.50$ & $2.54 \pm 0.53$ & 0.43 & $2.42 \pm 0.36$ & $2.47 \pm 0.41$ & 0.35 & $2.15 \pm 0.49$ & $2.25 \pm 0.49$ & 0.19 & $2.07 \pm 0.44$ & $2.15 \pm 0.41$ & 0.16 \\
\hline Acute gain & NA & NA & $\mathrm{NA}$ & $1.40 \pm 0.36$ & $1.46 \pm 0.44$ & 0.38 & NA & NA & $\mathrm{NA}$ & $1.05 \pm 0.45$ & $1.14 \pm 0.43$ & 0.2 \\
\hline At 9 months & $2.36 \pm 0.53$ & $2.47 \pm 0.62$ & 0.2 & $2.11 \pm 0.44$ & $2.35 \pm 0.53$ & $<0.001$ & $2.17 \pm 0.46$ & $2.29 \pm 0.52$ & 0.1 & $1.94 \pm 0.46$ & $2.10 \pm 0.50$ & 0.028 \\
\hline Late lumen loss (LLL) * & $0.10 \pm 0.35$ & $0.04 \pm 0.35$ & 0.29 & $0.29 \pm 0.33$ & $0.14 \pm 0.37$ & 0.004 & $-0.01 \pm 0.35$ & $-0.04 \pm 0.29$ & 0.46 & $0.13 \pm 0.38$ & $0.06 \pm 0.35$ & 0.21 \\
\hline \multicolumn{13}{|c|}{ Diameter stenosis (\%) } \\
\hline Pre-procedure & NA & NA & NA & $60.8 \pm 11.1$ & $60.8 \pm 10.8$ & 1.0 & NA & NA & NA & $60.8 \pm 11.1$ & $60.8 \pm 10.8$ & 1.0 \\
\hline Post-procedure & $14.0 \pm 8.4$ & $15.8 \pm 9.2$ & 0.19 & $9.5 \pm 6.4$ & $11.3 \pm 5.8$ & 0.039 & $16.8 \pm 10.1$ & $16.5 \pm 8.7$ & 0.78 & $20.6 \pm 8.4$ & $21.0 \pm 7.4$ & 0.73 \\
\hline At 9 months & $14.5 \pm 10.4$ & $17.4 \pm 13.2$ & 0.12 & $19.2 \pm 12.0$ & $16.1 \pm 12.6$ & 0.09 & $13.1 \pm 10.7$ & $15.8 \pm 9.2$ & 0.08 & $24.5 \pm 12.4$ & $23.9 \pm 12.5$ & 0.74 \\
\hline \multicolumn{13}{|l|}{ Binary restenosis (\%) } \\
\hline At 9 months & $1.3(1 / 80)$ & $3.8(3 / 79)$ & 0.37 & $3.3(3 / 90)$ & $4.4(4 / 91)$ & 1.0 & $1.1(1 / 87)$ & $1.1(1 / 89)$ & 1.0 & $5.6(5 / 90)$ & $5.5(5 / 91)$ & 1.0 \\
\hline
\end{tabular}

Table 3. Clinical outcomes at 12-month follow-up.

\begin{tabular}{|c|c|c|c|c|}
\hline & $\begin{array}{l}\text { BuMA Supreme } \\
\text { SES }\left(n=82^{*}\right)\end{array}$ & $\begin{array}{l}\text { Resolute-type ZES } \\
\qquad(n=87)\end{array}$ & $\begin{array}{l}\text { Difference } \\
{[95 \% \mathrm{Cl}]}\end{array}$ & $p$-value \\
\hline \multicolumn{5}{|l|}{ Individual endpoints } \\
\hline Death, all & $2(2.4)$ & $2(2.3)$ & $0.1 \%[-4.4 \%, 4.7 \%]$ & 1.00 \\
\hline Cardiac death & $1(1.2)$ & $1(1.1)$ & $0.1 \%[-3.2 \%, 3.3 \%]$ & 1.00 \\
\hline Myocardial infarction, all & $1(1.2)$ & $3(3.4)$ & $-2.2 \%[-6.7 \%, 2.3 \%]$ & 0.62 \\
\hline Periprocedural MI* & $1(1.2)$ & $2(2.3)$ & $-1.1 \%[-5.0 \%, 2.9 \%]$ & 1.00 \\
\hline Spontaneous MI** & $0(0)$ & $1(1.1)$ & $-1.1 \%[-3.4 \%, 1.1 \%]$ & 1.00 \\
\hline TV-MI & $1(1.2)$ & $2(2.3)$ & $-1.1 \%[-5.0 \%, 2.9 \%]$ & 1.00 \\
\hline TLR, all & $3(3.7)$ & $6(6.9)$ & $-3.2 \%[-9.9 \%, 3.5 \%]$ & 0.50 \\
\hline Clinically indicated TLR & $2(2.4)$ & $3(3.4)$ & $-1.0 \%[-6.1 \%, 4.1 \%]$ & 1.00 \\
\hline TVR, all & $5(6.1)$ & $9(10.3)$ & $-4.2 \%[-12.5 \%, 4.0 \%]$ & 0.32 \\
\hline Clinically indicated TVR & $4(4.9)$ & $5(5.7)$ & $-0.9 \%[-7.6 \%, 5.9 \%]$ & 1.00 \\
\hline \multicolumn{5}{|l|}{ Composite clinical endpoint } \\
\hline Composite of cardiac death, TV-MI and CI-TLR (DoCE) & $4(4.9)$ & $5(5.7)$ & $-0.9 \%[-7.6 \%, 5.9 \%]$ & 1.00 \\
\hline Composite of cardiac death and TV-MI & $2(2.4)$ & $2(2.3)$ & $0.1 \%[-4.4 \%, 4.7 \%]$ & 1.00 \\
\hline \multicolumn{5}{|l|}{ Stent thrombosis } \\
\hline Definite or probable stent thrombosis & $0(0)$ & $0(0)$ & $0.0 \%$ & NA \\
\hline \multicolumn{5}{|c|}{$\begin{array}{l}\text { Data are expressed as } n(\%) \text {. Analyses were performed based on the principle of intention-to-treat. \#One patient in SES group refused } 12-\text { month } \\
\text { follow-up. *Defined according to SCAI definition }{ }^{11} .{ }^{* *} \text { Defined according to third universal definition }{ }^{10} \text {. "One TLR in the SES group and three TLRs in the } \\
\text { ZES group were adjudicated as "non-clinically indicated TLR" due to the absence of symptom or functional assessment. DoCE: device-oriented } \\
\text { composite endpoint; MI: myocardial infarction; NA: not available; TLR: target lesion revascularisation; TV-MI: target vessel myocardial infarction; } \\
\text { TVR: target vessel revascularisation }\end{array}$} \\
\hline
\end{tabular}




\section{LATE LUMEN LOSS}

In the present trial, the LLL of the BuMA Supreme SES $(0.29 \pm 0.33 \mathrm{~mm})$ was numerically larger than anticipated based on the previous study of its predecessor $(0.24 \pm 0.33 \mathrm{~mm})^{15}$. Reasons for this discrepancy could reside in differences in study background (e.g., patients, lesion types, lesion length, procedural characteristics such as the degree of acute gain and residual stenosis) and in dissimilar methodologies of the angiographic core laboratories. Moreover, the LLL in the Resolute-type ZES group of the present trial $(0.14 \pm 0.37 \mathrm{~mm})$ was lower than the LLL observed in the Resolute first-in-man (FIM) trial $(0.22 \pm 0.27 \mathrm{~mm})$ which, in addition, was analysed by another core lab using a different methodology ${ }^{16}$. It might be related to differences in baseline procedure. Acute gain (in-stent) of Resolute ZES in the current trial was lower than the one in the Resolute FIM trial $(1.46 \pm 0.64 \mathrm{~mm}$ vs. $1.93 \pm 0.45 \mathrm{~mm}$ ), whereas residual percent stenosis in the Resolute ZES group in the current trial was greater than the one in the Resolute FIM trial $(11.3 \pm 5.8 \%$ vs. $3.36 \pm 8.54 \%)$. Mauri et al reported that decreased acute gain and increased residual stenosis were associated with increased LLL (estimated effect [mm]: 0.17 with acute gain [per mm], and -0.0097 with residual percent stenosis [per $1 \%])^{17}$. The differences in these parameters might be related to the difference in LLL between the two trials.

When PIONEER-like lesions, treated with a Resolute-type ZES, were selected from the Resolute all-comers trial, the angiographic LLL at 13 months, analysed by the core lab of the present study, was $0.19 \pm 0.26 \mathrm{~mm}^{7}$. Considering this, the relatively low LLL for the second and third iterations of the Resolute ZES may be seen in a different light and are less surprising.

\section{OTHER ANGIOGRAPHIC PARAMETERS AND CLINICAL EFFICACY}

Although in the current trial the BuMA Supreme SES did not meet the non-inferiority criterion in in-stent LLL, there was no betweengroup difference in in-segment percent DS (25 $\pm 13 \%$ vs. $24 \pm 13 \%)$. For both DES groups the in-segment percent DS was within the range of data seen with DES that have recently been approved by the Food and Drug Administration (FDA), as has been reported by the ESC/EAPCI task force on the evaluation of coronary stents in Europe in their executive summary for the European Union ${ }^{18}$. In addition, the 12-month DoCE rates were comparably low for both treatment arms (4.9\% vs. $5.7 \%)$, and in both treatment arms there was no case of definite or probable stent thrombosis.

\section{THE CLINICAL SIGNIFICANCE OF LLL AND REGULATORY PERSPECTIVE}

In the early days of balloon angioplasty, there was no quantitative method to assess the respective contribution of constrictive remodelling and neointimal proliferation. With the advent of quantitative angiography, late lumen loss, defined as a change in minimum lumen diameter between post-procedure and follow-up, was developed as a continuous variable to define restenosis and has for more than a quarter of a century remained the gold standard for regulatory bodies in the assessment of the "antirestenotic" efficacy of coronary devices ${ }^{19}$.
In the bare metal stent era, the LLL in absolute value was paradoxically doubled $(0.65 \pm 0.57 \mathrm{~mm})$ as compared to balloon angioplasty $(0.32 \pm 0.47 \mathrm{~mm})$, although minimal lumen diameter, binary restenosis rate, and target lesion revascularisation rate were improved ${ }^{20}$. LLL of a metallic coronary stent reflected exclusively the neointimal proliferation as the stent prevented constrictive vascular remodelling $^{21}$. After the emergence of DES, LLL was reduced to a relatively low value, but the "near eradication" of intra-stent neointima was not per se a criterion of device safety. In the RAVEL trial, the first-generation CYPHER ${ }^{\circledR}$ (Cordis, Cardinal Health, Milpitas, CA, USA) SES had no LLL at all $(-0.01 \pm 0.33 \mathrm{~mm})$, but the increase in late and very late adverse events with this type of DES showed clearly that LLL was a rather unsuitable parameter to predict the efficacy and long-term safety of this device ${ }^{22,23}$. A very low LLL may indeed reflect a delayed and incomplete healing process with uncovered and malapposed struts, only seen on optical coherence tomography $(\mathrm{OCT})^{24}$. Despite these facts, LLL remained a standard measure of the performance of new coronary stents and scaffolds ${ }^{18}$.

Angiographic LLL has been used for evaluating the process of neointimal hyperplasia and late constrictive remodelling in clinical trials with balloon angioplasty and stents, because the LLL was considered a robust continuous parameter that required a smaller sample size than the traditional binary restenosis. However, in the current era of DES, the clinical significance of comparing DES with very low LLL is debatable. Pocock et al, in data from a pooled analysis, showed that, within a range of relatively low LLL values (up to $1.0 \mathrm{~mm}$ ), differences in LLL were not associated with a significant difference in the target lesion revascularisation rate ${ }^{18,25}$. In contrast, a mild or moderately (certainly not an excessively) increased LLL might be favourable in terms of completeness of stent coverage ${ }^{24}$.

The BuMA Supreme stent was designed to elute $92 \%$ of the drug in 28 days and leave a drug level in the artery wall 60 days after implantation of less than $1 \mathrm{ng} / \mathrm{mg}$ - a concentration that is below the therapeutic level of prevention of neointimal progression, allowing early neointimal coverage (Figure 2). In the BuMA-OCT randomised trial at three-month follow-up, the BuMA stent had a more favourable neointimal coverage than the PLA polymer-based EXCEL SES (JW Medical Systems, Weihai, China), which is characterised by drug elution during a much longer period of time (180 days $)^{8}$. The Endeavor $^{\circledR}$ zotarolimus-eluting stent (E-ZES) (Medtronic) was similarly designed to complete drug elution within two weeks ${ }^{26}$. Interestingly, although E-ZES had a greater in-stent LLL compared to the TAXUS ${ }^{\text {TM }}$ paclitaxel-eluting stent (PES) (Boston Scientific, Marlborough, MA, USA) in the ENDEAVOR IV randomised control trial $(0.67 \pm 0.49 \mathrm{~mm}$ vs. $0.42 \pm 0.50 \mathrm{~mm}, \mathrm{p}<0.001)$, E-ZES was non-inferior to PES with rates of target vessel failure $6.6 \%$ versus $7.1 \%$, respectively $\left(\mathrm{p}_{\text {non-inferiority }}<0.001\right)^{27}$. It is notable that regulatory bodies in many countries, such as the FDA in the USA, approved the E-ZES holding clinical outcomes in great account.

The ultimate treatment goal of stenting a narrowed coronary segment is to re-establish optimal hyperaemic blood supply to the subtended myocardium, which today can be quantified by a functional test such as fractional flow reserve (FFR). Future trials and 
regulatory bodies may embody a combined angiographic and functional approach as criteria for approval. Thus, there is currently a need to establish an optimal parameter to validate stent performance that should precisely reflect improvements in functionality and reductions in adverse clinical event risk.

\section{Limitations}

The study was powered for the primary endpoint only; clinical outcomes are only hypothesis-generating. The sample size calculation was based on data of the first-in-man study of the Resolute ZES, which was analysed by a different core laboratory.

\section{Conclusions}

The trial did not meet its primary endpoint of non-inferiority in in-stent LLL at nine-month angiographic follow-up. Nevertheless, several other angiographic parameters such as percent diameter stenosis and binary restenosis rate were similar for both stents. One-year clinical event rates, although obtained in a relatively small patient population, were comparably low with both devices. Both this and future trials will further explore whether or not the unique pharmacokinetic properties of this stent impact on long-term outcomes.

\section{Impact on daily practice}

Nine months after the implantation of the novel BuMA Supreme sirolimus-eluting stent, the trial did not meet its primary endpoint of non-inferiority in terms of angiographic late lumen loss. Nevertheless, several other angiographic parameters and clinical endpoints were similar to the comparator device, suggesting that, in the current drug-eluting stent era, the clinical significance of the parameter late lumen loss may be limited and that its suitability for predicting the efficacy and safety of novel devices is debatable.

\section{Acknowledgements}

The authors would like to acknowledge the invaluable assistance of the members of the data safety monitoring board (DSMB), H. Boersma (Chairman), Erasmus University Medical Center, Rotterdam, H. Suryapranata, Radboud University Nijmegen Medical Center, and J. Ottervanger, Isala Klinieken, Zwolle, and the members of the clinical events committee (CEC), E. McFadden, Cork University Hospital, Scot Garg, Royal Blackburn Hospital, and Benno J.W.M. Rensing, St. Antonius Hospital, Nieuwegein.

\section{Funding}

This study was funded by SINOMED, Beijing, China.

\section{Guest Editor}

This paper was guest edited by Adnan Kastrati, MD; Deputy Director of Department Cardiovascular Diseases, Deutsches Herzzentrum München, Munich, Germany.

\section{Conflict of interest statement}

C. von Birgelen has been an unpaid consultant to several device manufacturing companies; Thoraxcentrum Twente has received institutional research funding from AstraZeneca, Biotronik, Boston Scientific, and Medtronic. P.W. Serruys, M. Sabaté, and Y. Onuma are members of the Advisory Board for Abbott Vascular. P.W. Serruys is a scientific medical consultant. The other authors have no conflicts of interest to declare. The Guest Editor has no conflicts of interest to declare.

\section{References}

1. Stone GW, Rizvi A, Sudhir K, Newman W, Applegate RJ, Cannon LA, Maddux JT, Cutlip DE, Simonton CA, Sood P, Kereiakes DJ; SPIRIT IV Investigators. Randomized comparison of everolimus- and paclitaxel-eluting stents. 2-year follow-up from the SPIRIT (Clinical Evaluation of the XIENCE V Everolimus Eluting Coronary Stent System) IV trial. J Am Coll Cardiol. 2011;58:19-25.

2. Räber L, Magro M, Stefanini GG, Kalesan B, van Domburg RT, Onuma Y, Wenaweser P, Daemen J, Meier B, Jüni P, Serruys PW, Windecker S. Very late coronary stent thrombosis of a newer-generation everolimus-eluting stent compared with early-generation drugeluting stents: a prospective cohort study. Circulation. 2012;125: 1110-21.

3. Jensen LO, Thayssen P, Christiansen EH, Tilsted HH, Maeng M, Hansen KN, Kaltoft A, Hansen HS, Botker HE, Krusell LR, Ravkilde J, Madsen M, Thuesen L, Lassen JF; SORT OUT IV Investigators. 2-year patient-related versus stent-related outcomes: the SORT OUT IV (Scandinavian Organization for Randomized Trials With Clinical Outcome IV) Trial. J Am Coll Cardiol. 2012;60:1140-7.

4. Palmerini T, Biondi-Zoccai G, Della Riva D, Mariani A, Sabaté M, Smits PC, Kaiser C, D’Ascenzo F, Frati G, Mancone M, Genereux P, Stone GW. Clinical outcomes with bioabsorbable polymer- versus durable polymer-based drug-eluting and baremetal stents: evidence from a comprehensive network meta-analysis. J Am Coll Cardiol. 2014;63:299-307.

5. Xu B, Gao R, Yang Y, Cao X, Qin L, Li Y, Li Z, Li X, Lin H, Guo Y, Ma Y, Wang J, Nie S, Xu L, Cao E, Guan C, Stone GW; PANDA III Investigators. Biodegradable Polymer-Based SirolimusEluting Stents With Differing Elution and Absorption Kinetics: The PANDA III Trial. J Am Coll Cardiol. 2016;67:2249-58.

6. von Birgelen C, Kok MM, van der Heijden LC, Danse PW, Schotborgh CE, Scholte M, Gin RMTJ, Somi S, van Houwelingen KG, Stoel MG, de Man FHAF, Louwerenburg JHW, Hartmann M, Zocca P, Linssen GCM, van der Palen J, Doggen CJM, Lowik MM. Very thin strut biodegradable polymer everolimuseluting and sirolimus-eluting stents versus durable polymer zotarolimus-eluting stents in allcomers with coronary artery disease (BIO-RESORT): a three-arm, randomised, non-inferiority trial. Lancet. 2016;388:2607-17.

7. Serruys PW, Silber S, Garg S, van Geuns RJ, Richardt G, Buszman PE, Kelbaek H, van Boven AJ, Hofma SH, Linke A, Klauss V, Wijns W, Macaya C, Garot P, DiMario C, Manoharan G, 
Kornowski R, Ischinger T, Bartorelli A, Ronden J, Bressers M, Gobbens P, Negoita M, van Leeuwen F, Windecker S. Comparison of zotarolimus-eluting and everolimus-eluting coronary stents. $N$ Engl J Med. 2010;363:136-46.

8. Qian J, Zhang YJ, Xu B, Yang YJ, Yan HB, Sun ZW, Zhao YL, Tang YD, Gao Z, Chen J, Cui JG, Mintz GS, Gao RL. Optical coherence tomography assessment of a PLGA-polymer with electro-grafting base layer versus a PLA-polymer sirolimus-eluting stent at three-month follow-up: the BuMA-OCT randomised trial. EuroIntervention. 2014;10:806-14.

9. Udipi K, Melder RJ, Chen M, Cheng P, Hezi-Yamit A, Sullivan C, Wong J, Wilcox J. The next generation Endeavor Resolute Stent: role of the BioLinx Polymer System. EuroIntervention. 2007;3:137-9.

10. von Birgelen C, van der Heijden LC, Basalus MW, Kok MM, Sen H, Louwerenburg HW, van Houwelingen KG, Stoel MG, de Man FH, Linssen GC, Tandjung K, Doggen CJ, van der Palen J, Löwik MM. Five-Year Outcome After Implantation of Zotarolimusand Everolimus-Eluting Stents in Randomized Trial Participants and Nonenrolled Eligible Patients: A Secondary Analysis of a Randomized Clinical Trial. JAMA Cardiol. 2017;2:268-76.

11. von Birgelen C, Sen H, Lam MK, Danse PW, Jessurun GA, Hautvast RW, van Houwelingen GK, Schramm AR, Gin RM, Louwerenburg JW, de Man FH, Stoel MG, Löwik MM, Linssen GC, Saïd SA, Nienhuis MB, Verhorst PM, Basalus MW, Doggen CJ, Tandjung K. Third-generation zotarolimus-eluting and everolimuseluting stents in all-comer patients requiring a percutaneous coronary intervention (DUTCH PEERS): a randomised, single-blind, multicentre, non-inferiority trial. Lancet. 2014;383:413-23.

12. Cutlip DE, Windecker S, Mehran R, Boam A, Cohen DJ, van Es GA, Steg PG, Morel MA, Mauri L, Vranckx P, McFadden E, Lansky A, Hamon M, Krucoff MW, Serruys PW; Academic Research Consortium. Clinical end points in coronary stent trials: a case for standardized definitions. Circulation. 2007;115:2344-51.

13. Thygesen K, Alpert JS, Jaffe AS, Simoons ML, Chaitman BR, White HD, Joint ESC/ACCF/AHA/WHF Task Force for the Universal Definition of Myocardial Infarction, Katus HA, Lindahl B, Morrow DA, Clemmensen PM, Johanson P, Hod H, Underwood R, Bax JJ, Bonow RO, Pinto F, Gibbons RJ, Fox KA, Atar D, Newby LK, Galvani M, Hamm CW, Uretsky BF, Steg PG, Wijns W, Bassand JP, Menasche P, Ravkilde J, Ohman EM, Antman EM, Wallentin LC, Armstrong PW, Simoons ML, Januzzi JL, Nieminen MS, Gheorghiade M, Filippatos G, Luepker RV, Fortmann SP, Rosamond WD, Levy D, Wood D, Smith SC, Hu D, Lopez-Sendon JL, Robertson RM, Weaver D, Tendera M, Bove AA, Parkhomenko AN, Vasilieva EJ, Mendis S. Third universal definition of myocardial infarction. Circulation. 2012;126:2020-35.

14. Moussa ID, Klein LW, Shah B, Mehran R, Mack MJ, Brilakis ES, Reilly JP, Zoghbi G, Holper E, Stone GW; Society for Cardiovascular Angiography and Interventions. Consideration of a new definition of clinically relevant myocardial infarction after coronary revascularization: an expert consensus document from the
Society for Cardiovascular Angiography and Interventions (SCAI). Catheter Cardiovasc Interv. 2014;83:27-36.

15. Chen X, Tian R, Wang G, Shi D, Wang Z, Chi Y, Dai W, Wang C, Lu C. A perspective multi center parallel controlled of BuMA $^{\mathrm{TM}}$ vs. Endeavor clinical trail program. Chin J Intervent Cardiol. 2013;3:137-41.

16. Meredith IT, Worthley S, Whitbourn R, Walters DL, McClean D, Horrigan M, Popma JJ, Cutlip DE, DePaoli A, Negoita M, Fitzgerald PJ; RESOLUTE Investigators. Clinical and angiographic results with the next-generation resolute stent system: a prospective, multicenter, first-in-human trial. JACC Cardiovasc Interv. 2009;2:977-85.

17. Mauri L, Orav EJ, Candia SC, Cutlip DE, Kuntz RE. Robustness of late lumen loss in discriminating drug-eluting stents across variable observational and randomized trials. Circulation. 2005;112:2833-9.

18. Byrne RA, Serruys PW, Baumbach A, Escaned J, Fajadet J, James S, Joner M, Oktay S, Jüni P, Kastrati A, Sianos G, Stefanini GG, Wijns W, Windecker S. Report of a European Society of Cardiology-European Association of Percutaneous Cardiovascular Interventions task force on the evaluation of coronary stents in Europe: executive summary. Eur Heart J. 2015;36:2608-20.

19. Serruys PW, Onuma Y, Ormiston JA, de Bruyne B, Regar E, Dudek D, Thuesen L, Smits PC, Chevalier B, McClean D, Koolen J, Windecker S, Whitbourn R, Meredith I, Dorange C, Veldhof S, Miquel-Hebert K, Rapoza R, Garcia-Garcia HM. Evaluation of the second generation of a bioresorbable everolimus drug-eluting vascular scaffold for treatment of de novo coronary artery stenosis: six-month clinical and imaging outcomes. Circulation. 2010;122:2301-12.

20. Serruys PW, de Jaegere P, Kiemeneij F, Macaya C, Rutsch W, Heyndrickx G, Emanuelsson H, Marco J, Legrand V, Materne P, et al. A comparison of balloon-expandable-stent implantation with balloon angioplasty in patients with coronary artery disease. Benestent Study Group. N Engl J Med. 1994;331:489-95.

21. Jensen LO, Maeng M, Thayssen P, Villadsen A, Krusell L, Botker HE, Pedersen KE, Aaroe J, Christiansen EH, Vesterlund T, Hansen KN, Ravkilde J, Tilsted HH, Lassen JF, Thuesen L. Late lumen loss and intima hyperplasia after sirolimus-eluting and zotarolimus-eluting stent implantation in diabetic patients: the diabetes and drug-eluting stent (DiabeDES III) angiography and intravascular ultrasound trial. EuroIntervention. 2011;7:323-31.

22. Morice MC, Serruys PW, Sousa JE, Fajadet J, Ban Hayashi E, Perin M, Colombo A, Schuler G, Barragan P, Guagliumi G, Molnar F, Falotico R; RAVEL Study Group. Randomized Study with the Sirolimus-Coated Bx Velocity Balloon-Expandable Stent in the Treatment of Patients with de Novo Native Coronary Artery Lesions. A randomized comparison of a sirolimus-eluting stent with a standard stent for coronary revascularization. $N$ Engl J Med. 2002;346:1773-80. 23. Daemen J, Kukreja N, van Twisk PH, Onuma Y, de Jaegere PP, van Domburg R, Serruys PW. Four-year clinical follow-up of the rapamycin-eluting stent evaluated at Rotterdam Cardiology Hospital registry. Am J Cardiol. 2008;101:1105-11. 
24. Kim JS, Jang IK, Kim JS, Kim TH, Takano M, Kume T, Hur NW, Ko YG, Choi D, Hong MK, Jang Y. Optical coherence tomography evaluation of zotarolimus-eluting stents at 9-month follow-up: comparison with sirolimus-eluting stents. Heart. 2009;95:1907-12.

25. Pocock SJ, Lansky AJ, Mehran R, Popma JJ, Fahy MP, Na Y, Dangas G, Moses JW, Pucelikova T, Kandzari DE, Ellis SG, Leon MB, Stone GW. Angiographic surrogate end points in drugeluting stent trials: a systematic evaluation based on individual patient data from 11 randomized, controlled trials. J Am Coll Cardiol. 2008;51:23-32.

26. Bridges J, Cutlip D. Advances in drug eluting stents - focus on the Endeavor $\left({ }^{\circledR}\right)$ zotarolimus stent. Med Devices (Auckl). 2009;2:1-8.

27. Leon MB, Mauri L, Popma JJ, Cutlip DE, Nikolsky E, O'Shaughnessy C, Overlie PA, McLaurin BT, Solomon SL, Douglas JS Jr, Ball MW, Caputo RP, Jain A, Tolleson TR, Reen BM 3rd, Kirtane AJ, Fitzgerald PJ, Thompson K, Kandzari DE; ENDEAVOR IV Investigators. A randomized comparison of the
Endeavor zotarolimus-eluting stent versus the TAXUS paclitaxeleluting stent in de novo native coronary lesions 12-month outcomes from the ENDEAVOR IV trial. J Am Coll Cardiol. 2010;55:543-54.

28. Serruys PW, Ruygrok P, Neuzner J, Piek JJ, Seth A, Schofer JJ, Richardt G, Wiemer M, Carrié D, Thuesen L, Boone E, MiquelHerbert K, Daemen J. A randomised comparison of an everolimuseluting coronary stent with a paclitaxel-eluting coronary stent: the SPIRIT II trial. EuroIntervention. 2006;2:286-94.

\section{Supplementary data}

Supplementary Appendix. Details of the protocol and the procedural results in the PIONEER trial.

Supplementary Table 1. Interventional procedure.

The supplementary data are published online at:

http://www.pcronline.com/

eurointervention/132nd_issue/332 


\section{Supplementary data}

\section{Supplementary Appendix. Details of the protocol and the procedural results in the PIONEER trial}

\section{The eligibility criteria of the PIONEER trial}

Age 18 years or older; presence of stable or unstable angina or silent ischaemia with clinical evidence of ischaemic heart disease and/or positive territorial functional study; presence of one or two separate, de novo target lesions (a single target lesion per major epicardial territory) with a 50-99\% lumen diameter stenosis in a reference vessel of 2.5-4.5 mm (visually determined), and a target lesion length that allowed treatment with a single study stent; coronary flow grade 2 or 3 according to the Thrombolysis In Myocardial Infarction (TIMI) classification in all target vessels.

\section{The exclusion criteria of the PIONEER trial}

Female of child-bearing potential; evolving myocardial infarction; bifurcated target lesion involving a side branch $>2.0 \mathrm{~mm}$; target lesion in the left main artery; aorto-ostial target lesion; target lesion with presence of angiographically visible thrombus; restenotic target lesion; left ventricular ejection fraction $<30 \%$; renal insufficiency (e.g., serum creatinine $>2.5$ $\mathrm{mg} / \mathrm{dL}$, creatinine clearance $\leq 30 \mathrm{~mL} / \mathrm{min}$, or patient treated by dialysis); intolerance to aspirin, heparin, antiplatelet medication specified for use in the study, sirolimus, zotarolimus, or cobalt-chromium.

\section{Definition of the secondary endpoint of the PIONEER trial}

(1) Acute device success: post-procedural DS $<30 \%$ using the assigned stent.

(2) Procedural success: device success without the occurrence of cardiac death, target vessel myocardial infarction (TV-MI; i.e., MI not clearly attributable to a non-intervention vessel), or target lesion revascularisation (TLR) during index hospitalisation.

(3) A device-oriented composite endpoint (DoCE): defined as the composite of CD, TV-MI, and clinically indicated TLR (CI-TLR).

(4) Clinically indicated TLR: defined as percent diameter stenosis $\geq 50 \%$ (core lab QCA assessment) AND if one of the following occurs:

- a positive history of recurrent angina pectoris, presumably related to the target vessel; 
- objective signs of ischaemia at rest (ECG changes) or during exercise test (or equivalent), presumably related to the target vessel;

- abnormal results of any invasive functional diagnostic test (e.g., Doppler flow velocity reserve, fractional flow reserve).

A TLR with a diameter stenosis $\geq 70 \%$ even in the absence of the above-mentioned ischaemic signs or symptoms is also considered clinically indicated.

\section{Sample size calculation of the PIONEER trial}

The trial was powered for testing non-inferiority for the primary endpoint at nine-month angiographic follow-up. An LLL of $0.22 \mathrm{~mm}$ was assumed for both device groups, based on the Resolute first-in-human trial [16], in which the Brigham and Women’s Angiographic Core Laboratory in Boston, MA, USA, measured an LLL of $0.22 \pm 0.27 \mathrm{~mm}$. The noninferiority margin was set as $0.16 \mathrm{~mm}$, similar to the SPIRIT II trial [28]. Assuming an attrition rate of $10 \%, 84$ patients per arm were required to achieve $95 \%$ power to demonstrate non-inferiority with a one-sided type $\alpha$ error of 0.025 .

\section{Principal investigators and study chairman}

C. von Birgelen, MD, PhD (PI); Thoraxcentrum Twente, Enschede, the Netherlands

M. Sabaté, MD, PhD (PI); Clinic University Hospital, Barcelona, Spain

P.W. Serruys, MD, PhD (Study Chairman); Imperial College London, London, UK 
Supplementary Table 1. Interventional procedure.

\begin{tabular}{|c|c|c|c|c|c|c|}
\hline & \multicolumn{2}{|c|}{$\begin{array}{l}\text { BuMA Supreme } \\
\text { SES } \\
83 \text { patients (N) } \\
\text { /95 lesions (L) } \\
\end{array}$} & \multicolumn{2}{|c|}{$\begin{array}{l}\text { Resolute-type } \\
\text { ZES } \\
\text { 87 patients (N) } \\
\text { /101 lesions (L) } \\
\end{array}$} & \multirow[t]{2}{*}{$\begin{array}{l}\text { Difference } \\
\text { [95\% CI] }\end{array}$} & \multirow[t]{2}{*}{$p$-value } \\
\hline & $\mathbf{n}$ & & $\mathbf{n}$ & & & \\
\hline \multicolumn{7}{|l|}{ Before PCI } \\
\hline \multicolumn{7}{|l|}{ Target vessel location } \\
\hline Left anterior descending artery $\dagger$ & 95 & $46(48.4)$ & 101 & $39(38.6)$ & $9.8 \%[-4.0 \%, 23.6 \%]$ & 0.17 \\
\hline Left circumflex artery $\dagger$ & 95 & $19(20)$ & 101 & $28(27.7)$ & $-7.7 \%[-19.6 \%, 4.1 \%]$ & 0.21 \\
\hline Right coronary artery $\dagger$ & 95 & $30(31.6)$ & 101 & $34(33.7)$ & $-2.1 \%[-15.2 \%, 11.0 \%]$ & 0.76 \\
\hline ACC/AHA lesion class $\dagger$ & & & & & & 0.73 \\
\hline A & 95 & $4(4.2)$ & 100 & $3(3)$ & & \\
\hline B1 & 95 & $48(50.5)$ & 100 & $46(46)$ & & \\
\hline B2 & 95 & $43(45.3)$ & 100 & $51(51)$ & & \\
\hline $\mathbf{C}$ & 95 & $0(0)$ & 100 & $0(0)$ & & \\
\hline Moderate or severe calcification $\dagger$ & 93 & $20(21.5)$ & 97 & 18 (18.6) & $2.9[-8.4,14.3]$ & 0.61 \\
\hline TIMI score 0 or $1 \dagger$ & 91 & $1(1.1)$ & 96 & $0(0)$ & $1.1[-1.0,3.2]$ & 0.49 \\
\hline Reference vessel diameter $(\mathrm{mm}) \dagger+\uparrow$ & 91 & $2.57 \pm 0.43$ & 95 & $2.66 \pm 0.48$ & $-0.09[-0.22,0.04]$ & 0.19 \\
\hline Lesion length (mm) $\dagger+\uparrow$ & 91 & $13.15 \pm 6.42$ & 95 & $14.32 \pm 6.86$ & $-1.17[-3.10,0.75]$ & 0.23 \\
\hline Long lesion (length $>18 \mathrm{~mm}$ ) †† & 91 & $21(23.1)$ & 95 & $19(20.0)$ & $3.1[-8.7,14.9]$ & 0.61 \\
\hline Small vessel $(R V D \leq 2.75 \mathrm{~mm}) \dagger+\uparrow$ & 91 & $61(67.0)$ & 95 & $58(61.1)$ & $6.0[-7.8,19.7]$ & 0.4 \\
\hline Thrombus present $\dagger \dagger \S$ & 91 & $0(0)$ & 95 & $1(1.1)$ & $-1.1[-3.1,1.0]$ & 1.00 \\
\hline \multicolumn{7}{|l|}{ PCI procedure } \\
\hline \multicolumn{7}{|l|}{ Number of implanted stents } \\
\hline Per patient & 83 & $1.2 \pm 0.4$ & 87 & $1.3 \pm 0.6$ & $-0.1[-0.3,0.0]$ & 0.14 \\
\hline Per lesion & 95 & $1.1 \pm 0.2$ & 101 & $1.1 \pm 0.4$ & $-0.1[-0.2,0.0]$ & 0.08 \\
\hline \multicolumn{7}{|l|}{ Nominal stent diameter (mm) } \\
\hline Per patient & 83 & $2.98 \pm 0.42$ & 87 & $3.08 \pm 0.39$ & $-0.09[-0.21,0.03]$ & 0.14 \\
\hline Per lesion & 95 & $2.96 \pm 0.42$ & 101 & $3.08 \pm 0.45$ & $-0.12[-0.24,0.00]$ & $0.05 \#$ \\
\hline \multicolumn{7}{|l|}{ Total nominal stent length (mm) } \\
\hline 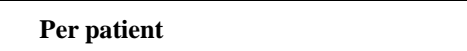 & 83 & $25.1 \pm 12.2$ & 87 & $26.1 \pm 12.3$ & $-1.0[-4.7,2.7]$ & 0.59 \\
\hline Per lesion & 95 & $21.9 \pm 8.8$ & 101 & $22.5 \pm 10.7$ & $-0.6[-3.3,2.2]$ & 0.69 \\
\hline Predilation performed & 83 & $66(79.5)$ & 87 & $56(64.4)$ & $15.2 \%[1.9 \%, 28.4 \%]$ & 0.03 \\
\hline Post-dilation performed & 83 & $31(37.3)$ & 87 & $42(48.3)$ & $-10.9 \%[-25.7 \%, 3.9 \%]$ & 0.15 \\
\hline Patients treated with allocated stent only & 83 & $81(97.6)$ & 87 & $83(95.4)$ & $2.2[-3.3,7.7]$ & 0.68 \\
\hline \multicolumn{7}{|l|}{ Successful outcome } \\
\hline Device success* & 93 & $90(96.8)$ & 99 & 94 (94.9) & $1.8 \%[-3.8 \%, 7.4 \%]$ & 0.72 \\
\hline Procedural success $^{* *}$ & 82 & 79 (96.3) & 85 & $80(94.1)$ & $2.2 \%[-4.2 \%, 8.7 \%]$ & 0.72 \\
\hline
\end{tabular}

Data are expressed as mean \pm SD or number (percentage).

Presented number (n) of lesions or patients with available data.

† Data were derived from eCRF (SES: N=83, L=95; ZES: N=87, L=91).

†† Data were based on core lab analysis with available QCA at pre-procedure (SES: N=81, L=92; ZES: N=83, L=95). 2 lesions in SES: lost film; 5 lesions in ZES: target lesion not recorded; 1 lesion in SES and 1 lesion in ZES: non-analysable due to the presence of a radiopaque marker of guidewire. 
ๆ One lesion in SES arm was not analysable due to TIMI 1 flow.

$\S$ One lesion in SES arm was not analysable due to guidewire.

* 192 lesions (SES: L=93; ZES: L=99) with residual diameter stenosis available were analysed.

** 167 patients (SES: L=82; ZES: L=85) with residual diameter stenosis available were analysed.

\# $\mathrm{p}=0.051$. 